CLINICAL STUDY

\title{
Delayed diagnosis of Sheehan's syndrome in a developed country: a retrospective cohort study
}

\author{
Cynthia Ramiandrasoa ${ }^{1}$, Frédéric Castinetti ${ }^{2}$, Isabelle Raingeard ${ }^{3}$, Patrick Fenichel ${ }^{4}$, Olivier Chabre $^{5}$, \\ Thierry Brue ${ }^{2}$ and Blandine Courbière ${ }^{1,6}$ \\ ${ }^{1}$ Department of Gynaecology, Obstetrics and Reproduction, AP-HM La Conception, 147 boulevard Baille, 13005 Marseille, France, ${ }^{2}$ Department of \\ Endocrinology, AP-HM La Timone, Aix-Marseille University, 264 rue Saint Pierre, 13385 Marseille Cedex 5 France, ${ }^{3}$ Department of Endocrinology, \\ Hôpital Lapeyronie, 371 Avenue du Doyen Gaston Giraud, 34295 Montpellier Cedex 5, France, ${ }^{4}$ Department of Endocrinology, Hôpital de l'Archet, \\ 151 Route Saint Antoine Ginestière, BP 3079, 06202 Nice Cedex 3, France, ${ }^{5}$ Department of Endocrinology, CHU Grenoble, allée des Sablons, \\ bâtiment Les Ecrins, 38043 Grenoble Cedex 9, France and ${ }^{6}$ Biogénotoxicologie, Santé Humaine et Environnement, IMBE (UMR 7263 - IRD 237/FR \\ CNRS 3098), Aix-Marseille Université, Faculté de Médecine, 27 boulevard Jean-Moulin, 13005 Marseille, France
}

(Correspondence should be addressed to B Courbière at Department of Gynaecology, Obstetrics and Reproduction, AP-HM La Conception; Email: blandine.courbiere@ap-hm.fr)

\begin{abstract}
Background: Little is known about Sheehan's syndrome (SS), even though it is believed that its incidence is low. The aims of this study were to determine the clinical features and diagnostic delay of SS and to ascertain whether early signs could have allowed earlier diagnosis.

Subjects and methods: All patients with SS diagnosed in reference units in the southeast of France between 1980 and 2011 were recruited for this study. Data on obstetrical history, clinical symptoms suggestive of hypopituitarism, early signs, hormone analysis, and magnetic resonance imaging were collected. Results: Of the 40 women found to have SS, 39 were studied. Mean delay in the diagnosis of SS was $9 \pm 9.7$ years. We found that four of the 35 assessable patients were diagnosed with agalactia, 16 of the 29 assessable ones with amenorrhea, 19 of the 39 with hypothyroidism, eight with acute adrenal insufficiency, and 15 with asthenia. Among the patients for whom there was a diagnostic delay of more than 1 year $(n=28)$, seven had headaches during the postpartum period, all assessable patients had agalactia, six of the 22 assessable ones had amenorrhea, seven of 28 had hypothyroidism, and 12 of 28 had asthenia. Conclusion: Most signs of SS are aspecific and classical signs such as agalactia and amenorrhea are often difficult to detect, which can explain the long diagnostic delay. We suggest that all women failing to lactate after postpartum hemorrhage (PPH) should be evaluated by measuring prolactin levels and women with signs such as amenorrhea and asthenia, even several years after PPH, should undergo a blood test including assessment of thyroxine, TSH, $0800 \mathrm{~h} \mathrm{ACTH-cortisol,} \mathrm{and} \mathrm{IGF1} \mathrm{levels.}$
\end{abstract}

European Journal of Endocrinology 169 431-438

\section{Introduction}

Postpartum hemorrhage ( $\mathrm{PPH})$ is the leading cause of maternal death in developing countries $(1,2)$. In developed countries, maternal mortality is 100-fold lower, but PPH remains the cause of maternal death for about ten women per 100000 births (2). In France, the incidence rate of $\mathrm{PPH}$ has been estimated to be 3.1 per 1000 deliveries (3). However, the mortality ratio due to hemorrhage has been reported to be 2.5 times higher than the mean European rate (2). The French confidential enquiry into maternal deaths concluded that $50 \%$ of maternal deaths from hemorrhage were avoidable (4). Although maternal death is a rare event, the morbidity associated with severe hemorrhage remains a major concern. In the circumstances of massive PPH, shock, severe hypotension, and vasospasm may lead to anterior pituitary ischemia and necrosis, called Sheehan's syndrome (SS).
SS is defined as a result of ischemic pituitary necrosis due to severe PPH and/or decreased blood pressure (5). Among the scarce publications found on SS, many have been reported in developing countries, where SS represents one of the most common causes of hypopituitarism and thus a big health issue $(6,7)$.

With better obstetrical help and thanks to the progress in anesthesiology and reanimation, the incidence of SS has decreased. It now theoretically ranges from 0.2 to 2.8 per 100000 women in developed countries (8). SS thus probably represents a rare cause of hypopituitarism $(9,10)$. However, in the retrospective study by Kristjansdottir et al. (10), the prevalence in Iceland in 2009 was reported to be higher than expected (5.1 per 100000 women), indicating that SS should not be ignored in developed countries.

SS might be underestimated in developed countries, as suggested by a wide range in the delay between 
delivery and the diagnosis of SS, from 1 month to 20 years $(10,11,12,13)$. Diagnosis can be difficult due to only subtle signs of hypopituitarism or misdiagnosis with Baby Blues syndrome. Therefore, SS is frequently misdiagnosed and incorrectly taken care of $(12,14,15)$.

The aims of this study were to determine the clinical features and diagnostic delay of SS in the southeast of France and also to ascertain whether early signs could have allowed earlier diagnosis of SS.

\section{Subjects and methods}

\section{Subjects}

We conducted a retrospective study on patients followed for SS in endocrinology units in four French tertiary teaching hospitals (Assistance Publique - Hôpitaux de Marseille; Hôpital Lapeyronie in Montpellier; Hôpital L'Archet in Nice; and Hôpital Nord in Grenoble). These four University teaching hospitals are reference units and record most patients with pituitary disorders in the southeast of France. We collected medical data from all patients with SS diagnosed between January 1980 and December 2011.

Data on circumstances and diagnostic delays were collected through obstetrical history research. Historical data were then collected by looking at the files of the respective endocrinology departments and at the results of the examination of patients during annual consultations about hypopituitarism. Clinical symptoms suggestive of hypopituitarism were sought in the medical records to find the reason for the initial consultation. In order to analyze the early signs that could have helped diagnose SS sooner, we included only patients $(n=28)$ for whom the diagnostic delay was over 1 year, with the 'earlier' diagnostic delay being defined to be under 1 year.

\section{Data collection during follow-up visits}

Obstetrical data were collected retrospectively to estimate the severity of PPH. Severe PPH was defined by loss of blood $>1000 \mathrm{ml}$, but we could not obtain data on the estimated blood loss. The degree of the severity of PPH was thus suggested by the presence or absence of blood transfusion, hysterectomy for hemostasis, and maternal intensive care unit (ICU) admission.

The patients were surveyed with regard to their health after childbearing with questions and clinical examination about aspecific symptoms (axillary and pubic hair loss, fatigue, intolerance to cold, puffy face, sparse hair in the armpit and pubic regions, and breast atrophy) and more specific symptoms of SS (agalactia and amenorrhea). Amenorrhea was defined by a lack of menses 3 months after delivery for a woman who does not breastfeed.
When diagnosed with SS, all patients had undergone initial hormonal evaluation (plasma thyroid-stimulating hormone (TSH), tri-iodothyronine $\left(\mathrm{T}_{3}\right)$, thyroxine $\left(\mathrm{T}_{4}\right)$, $0800 \mathrm{~h}$ adrenocorticotrophic hormone (ACTH)-cortisol, luteinizing hormone (LH), follicle-stimulating hormone (FSH), estradiol, prolactin (PRL), and insulin-like growth factor 1 (IGF1)) and imaging (magnetic resonance imaging (MRI) or computed tomography (CT) if contraindicated). Pituitary dysfunction led to substitutive hormone treatment. TSH deficiency was defined by low plasma $\mathrm{T}_{4}$ levels with low or inappropriately normal TSH levels. At the time of the diagnosis, patients who were already on $\mathrm{L}_{-} \mathrm{T}_{4}$ therapy and had normal $\mathrm{TSH}$ and $\mathrm{T}_{4}$ levels could not be evaluated. Withdrawal of $\mathrm{L}-\mathrm{T}_{4}$ therapy was not done. TSH deficiency was not clear as the patients were on $\mathrm{L}_{-} \mathrm{T}_{4}$ therapy at the time of SS diagnosis. Thyroperoxydase and thyroglobulin auto antibodies (anti-TG/TPO) and initial TSH were not detectable. ACTH deficiency was defined by a low cortisol level $(<100 \mathrm{nmol} / \mathrm{l})$ with a low or an inappropriately normal ACTH level at $0800 \mathrm{~h}$. Patients with a cortisol level $>300 \mathrm{nmol} / \mathrm{l}$ were considered not deficient. A synacthen test or an insulin tolerance test was at times performed if the cortisol level was in the low-to-normal range (100-300 nmol/l), depending on the investigator. When the test was not performed, data were considered incomplete. When the test was performed, peak cortisol level $>550 \mathrm{nmol} / \mathrm{l}$ was considered normal. Some patients were already on hydrocortisone therapy at the time of the diagnosis. These patients were diagnosed with corticotroph deficiency by their general practitioner or their gynecologist without considering that ACTH deficiency could be part of SS. When the patients were referred to the endocrinologist for non-specific signs, the diagnosis of ACTH deficiency due to SS was definitely confirmed. The patients were asked to take hydrocortisone the day before in one intake, followed by $24 \mathrm{~h}$ without the drug and then perform $0800 \mathrm{~h} \mathrm{ACTH}$ and cortisol sampling. Gonadotropin deficiency was defined by low plasma sex steroid levels with an inappropriate gonadotropin level (normal or low) and amenorrhea in non-hysterectomized patients. Somatotropin deficiency was defined by an IGF1 or growth hormone (GH) level $<3 \mu \mathrm{g} / \mathrm{l}$ when an insulin tolerance test was performed. Reference values of IGF1 varied according to age. PRL deficiency was defined by a normal level of PRL in the postpartum period and by a PRL level $<3 \mathrm{ng} / \mathrm{ml} 6$ weeks after delivery. For each of these parameters, mean data are presented with ranges and reference values.

The diagnosis of SS was based on the patient's obstetrical history and on laboratory data, including hormone levels and hormone stimulation test results, and MRI evaluation of the pituitary. Patients who had history of any disease that might have affected the pituitary such as cranial radiotherapy, severe head trauma, or head surgery were excluded from the study.

Informed consent for retrospective review of patient files was obtained from each patient as part of the 
regulatory process of our institutions, validated by the local ethical review board.

All data were analyzed using the Excel Software (Microsoft Corp.). Descriptive data are expressed as mean \pm s.E.M. and percentages. Some results are also expressed as medians and ranges. The percentage calculation was done by taking into account the missing data for each variable analyzed. Correlation calculations were done using the Spearman test or Mann-Whitney $U$ test, and results were considered significant if $P<0.05$.

\section{Results}

Forty cases of SS were diagnosed between 1980 and 2011. One patient born in 1927 was excluded because the major part of clinical data was missing. A total of 39 women with SS were thus studied. Mean age at the time of the diagnosis of SS was $38 \pm 7.7$ years (range: 19.5-55). As patients gave birth between 1963 and 2009 , mean delay in the diagnosis of SS was $9 \pm 9.7$ years (median: 7 years; range: 3 days to 36 years).

\section{Obstetrical histories}

Among the 39 patients, 38 had a massive PPH. One patient had presented anaphylactic hypotension shock at the time of delivery because of a latex allergy. Precise obstetrical data were not available for all the patients: $83.9 \%$ of the patients $(n=26 / 31)$ had blood transfusion for severe hemorrhage, $27.8 \%(n=10 / 36)$ had hysterectomy, and $62 \%(n=18 / 29)$ were transferred to the ICU. There was no correlation between the severity of PPH and diagnostic delay $(P=0.92$ with Spearman's test).

Table 1 Circumstances of the diagnosis of Sheehan's syndrome in a retrospective study of 39 patients.

\begin{tabular}{|c|c|c|c|c|c|c|c|c|c|c|c|}
\hline Patients & $\begin{array}{l}\text { Year of } \\
\text { diagnosis }\end{array}$ & $\begin{array}{l}\text { Diagnostic } \\
\text { delay (years) }\end{array}$ & $\begin{array}{l}\text { Blood } \\
\text { transfusion }\end{array}$ & HTT & ICU & Agalactia & Amenorrhea & Hypothyr & A & AAI & IRM \\
\hline 1 & 2002 & 8 & $Y$ & $Y$ & Y & $\mathrm{N}$ & HTT & $\mathrm{N}$ & $\mathrm{N}$ & Y & $E$ \\
\hline 2 & 2001 & 3 & $\mathrm{Y}$ & Y & Y & $\mathrm{N}$ & HTT & $\mathrm{Y}$ & $\mathrm{N}$ & $\mathrm{N}$ & a \\
\hline 3 & 2004 & 36 & NA & $\mathrm{N}$ & NA & $\mathrm{N}$ & $\mathrm{Y}$ & $\mathrm{Y}$ & $\mathrm{Y}$ & $\mathrm{N}$ & E \\
\hline 4 & 2004 & 9 & $\mathrm{Y}$ & $\mathrm{N}$ & $\mathrm{Y}$ & DA & $\mathrm{N}$ & $\mathrm{N}$ & $\mathrm{N}$ & $\mathrm{Y}$ & $\mathrm{PE}$ \\
\hline 5 & 1967 & $1 / 2$ & NA & NA & NA & $\mathrm{N}$ & $\mathrm{Y}$ & $\mathrm{N}$ & $\mathrm{N}$ & $\mathrm{N}$ & $\mathrm{E}$ \\
\hline 6 & 1988 & 2/12 & $\mathrm{Y}$ & $\mathrm{Y}$ & $Y$ & $\mathrm{~N}$ & HTT & $\mathrm{N}$ & $\mathrm{Y}$ & $\mathrm{N}$ & $E$ \\
\hline 7 & 1986 & $3 / 360$ & $\mathrm{Y}$ & Y & Y & Y & HTT & $\mathrm{N}$ & $\mathrm{N}$ & $\mathrm{N}$ & $E$ \\
\hline 8 & 1991 & 28 & NA & $\mathrm{N}$ & NA & $\mathrm{N}$ & $\mathrm{Y}$ & $\mathrm{N}$ & $\mathrm{N}$ & $\mathrm{N}$ & E \\
\hline 9 & 2000 & 6 & $\mathrm{Y}$ & $\mathrm{N}$ & $\mathrm{N}$ & $\mathrm{N}$ & $\mathrm{N}$ & $\mathrm{Y}$ & $\mathrm{N}$ & $\mathrm{N}$ & $E$ \\
\hline 10 & 2005 & 8 & NA & $\mathrm{N}$ & NA & $\mathrm{N}$ & $\mathrm{N}$ & $\mathrm{N}$ & $\mathrm{N}$ & $\mathrm{Y}$ & $\mathrm{E}$ \\
\hline 11 & 1997 & 2/12 & $\mathrm{Y}$ & Y & $\mathrm{Y}$ & $\mathrm{Y}$ & HTT & $\mathrm{Y}$ & $\mathrm{Y}$ & $\mathrm{N}$ & $\bar{a}$ \\
\hline 12 & 2005 & 24 & NA & $\mathrm{N}$ & NA & $\mathrm{N}$ & Y & $\mathrm{N}$ & $\mathrm{N}$ & $\mathrm{N}$ & E \\
\hline 13 & 1990 & 3 & $\mathrm{Y}$ & $\mathrm{N}$ & $\mathrm{Y}$ & $\mathrm{N}$ & Y & $\mathrm{Y}$ & $\mathrm{Y}$ & $\mathrm{N}$ & $\mathrm{a}$ \\
\hline 14 & 1990 & 11 & Y & Y & Y & $\mathrm{N}$ & HTT & $\mathrm{Y}$ & $\mathrm{N}$ & $\mathrm{N}$ & $E$ \\
\hline 15 & 2002 & 2 & NA & Y & NA & $\mathrm{N}$ & HTT & $Y$ & $\mathrm{Y}$ & $\mathrm{N}$ & Nor \\
\hline 16 & 1985 & 1 & $\mathrm{Y}$ & $\mathrm{N}$ & $Y$ & DA & $\mathrm{N}$ & $Y$ & $Y$ & $\mathrm{~N}$ & $\mathrm{E}$ \\
\hline 17 & 1995 & 19 & $\mathrm{~N}$ & $\mathrm{~N}$ & $\mathrm{~N}$ & $\mathrm{~N}$ & $\mathrm{~N}$ & $Y$ & $\mathrm{Y}$ & $\mathrm{N}$ & $E$ \\
\hline 18 & 2009 & $6 / 12$ & $Y$ & Y & $Y$ & $\mathrm{~N}$ & HTT & $\mathrm{N}$ & $Y$ & $\mathrm{~N}$ & $\bar{a}$ \\
\hline 19 & 2005 & 10 & $Y$ & $\mathrm{~N}$ & NA & $\mathrm{N}$ & Y & $\mathrm{N}$ & $\mathrm{N}$ & $\mathrm{N}$ & $E$ \\
\hline 20 & 1997 & 9 & NA & $\mathrm{N}$ & NA & $\mathrm{N}$ & Y & $\mathrm{N}$ & $\mathrm{N}$ & $\mathrm{N}$ & $\bar{E}$ \\
\hline 21 & 1985 & 7/12 & $Y$ & $\mathrm{~N}$ & $\mathrm{~N}$ & $Y$ & Y & $Y$ & $Y$ & $\mathrm{~N}$ & a \\
\hline 22 & 2006 & 28 & Y & $\mathrm{N}$ & $\mathrm{N}$ & $\mathrm{N}$ & $\mathrm{N}$ & $Y$ & $\mathrm{~N}$ & $Y$ & $\mathrm{E}$ \\
\hline 23 & 1989 & 8 & $Y$ & $\mathrm{~N}$ & $Y$ & $\mathrm{~N}$ & Y & $\mathrm{N}$ & $\mathrm{N}$ & $\mathrm{N}$ & $E$ \\
\hline 24 & 1990 & 17 & $Y$ & $\mathrm{~N}$ & Y & $\mathrm{N}$ & Y & $\mathrm{N}$ & $\mathrm{N}$ & $\mathrm{N}$ & $E$ \\
\hline 25 & 2008 & 3 & $Y$ & $\mathrm{~N}$ & $\mathrm{~N}$ & $\mathrm{~N}$ & Y & $Y$ & $Y$ & $\mathrm{~N}$ & $a$ \\
\hline 26 & 2000 & $4 / 12$ & $\mathrm{~N}$ & $\mathrm{~N}$ & $\mathrm{~N}$ & $\mathrm{~N}$ & Y & $\mathrm{N}$ & $\mathrm{N}$ & $\mathrm{N}$ & LE \\
\hline 27 & 2007 & 5 & $\mathrm{Y}$ & $\mathrm{N}$ & $Y$ & $\mathrm{~N}$ & Y & $Y$ & $\mathrm{Y}$ & $\mathrm{N}$ & $\mathrm{E}$ \\
\hline 28 & 2003 & $12 / 360$ & $Y$ & $\mathrm{~N}$ & Y & DA & $\mathrm{N}$ & $\mathrm{N}$ & $\mathrm{N}$ & $\mathrm{N}$ & LE \\
\hline 29 & 2000 & $1 / 12$ & $\mathrm{~N}$ & $\mathrm{~N}$ & Y & $Y$ & $\mathrm{~N}$ & $\mathrm{~N}$ & $\mathrm{~N}$ & $\mathrm{~N}$ & Nor \\
\hline 30 & 1999 & 2 & $Y$ & $\mathrm{~N}$ & $\mathrm{~N}$ & $\mathrm{~N}$ & $\mathrm{~N}$ & $Y$ & $\mathrm{~N}$ & $\mathrm{~N}$ & $\mathrm{a}$ \\
\hline 31 & 1992 & 27 & $Y$ & NA & $Y$ & $\mathrm{~N}$ & $\mathrm{~N}$ & $Y$ & $\mathrm{~N}$ & $\mathrm{~N}$ & NA \\
\hline 32 & 1984 & 8 & $Y$ & $\mathrm{~N}$ & $\mathrm{~N}$ & $\mathrm{~N}$ & Y & $Y$ & $\mathrm{Y}$ & $\mathrm{N}$ & Nor \\
\hline 33 & 1989 & $5 / 12$ & $\mathrm{~N}$ & $\mathrm{~N}$ & $\mathrm{~N}$ & DA & $\mathrm{N}$ & $\mathrm{N}$ & $\mathrm{N}$ & $\mathrm{Y}$ & $\mathrm{a}$ \\
\hline 34 & 1990 & $4 / 12$ & $Y$ & $\mathrm{~N}$ & $\mathrm{~N}$ & $\mathrm{~N}$ & $Y$ & $Y$ & $\mathrm{Y}$ & $\mathrm{N}$ & Nor \\
\hline 35 & 2002 & 14 & $Y$ & $\mathrm{~N}$ & NA & $\mathrm{N}$ & $\mathrm{N}$ & $Y$ & $Y$ & $\mathrm{~N}$ & $a$ \\
\hline 36 & 2003 & 12 & $\mathrm{~N}$ & NA & NA & $\mathrm{N}$ & $\mathrm{N}$ & $Y$ & $Y$ & $\mathrm{~N}$ & $\mathrm{E}$ \\
\hline 37 & 2003 & 17 & $Y$ & $Y$ & $\mathrm{Y}$ & $\mathrm{N}$ & HTT & $\mathrm{N}$ & $\mathrm{N}$ & $\mathrm{N}$ & $E$ \\
\hline 38 & 2009 & 7 & $\mathrm{~N}$ & $\mathrm{~N}$ & $\mathrm{~N}$ & $\mathrm{~N}$ & $Y$ & $\mathrm{~N}$ & $\mathrm{~N}$ & $\mathrm{~N}$ & $\bar{a}$ \\
\hline 39 & 2010 & 18 & $Y$ & Y & $Y$ & $\mathrm{~N}$ & HTT & $\mathrm{N}$ & $\mathrm{N}$ & $\mathrm{N}$ & $E$ \\
\hline
\end{tabular}

HTT, hysterectomy; DA, dopamine agonist; Y, yes; N, no; NA, not available; A, asthenia; ICU, intensive care unit; Hypothr, hypothyroidism; AAI, acute adrenal insufficiency; E, empty; PE, partially empty; a, atrophy; Nor, normal; LE, lack of enhancement after gadolinium treatment. 


\section{Clinical signs}

We compared signs at the time of the diagnosis with the retrospective evaluation (on the basis of the data collected) of signs suggestive of pituitary deficiencies in patients between delivery and the diagnosis of SS. The signs observed during diagnosis are summarized in Table 1. First, we evaluated the patients for agalactia. Among the 39 patients studied, four had received dopamine agonist therapy, which is systematically given to patients who do not want to breastfeed. These four patients could not be thus evaluated for agalactia. Of 35 patients evaluated, four $(n=4 / 35$ or $11 \%)$ had been diagnosed with agalactia. The other patients who had consulted not for agalactia but for other signs such as asthenia or amenorrhea could have had presented agalactia, considered in our study, as early signs. It was, however, not the reason for consultation in which SS was suggested. Second, we evaluated the patients for the presence of amenorrhea. Among the 39 patients, only 29 could be evaluated for amenorrhea because ten patients had undergone hysterectomy. Among the 29 remaining patients, $16(n=16 / 29$ or $55 \%)$ had been diagnosed with amenorrhea. Of the 39 patients, eight $(n=8 / 39$ or $20.5 \%)$ had consulted for genital and axillary hair loss. Of the 39 patients, $19(n=19 / 39$ or $48 \%$ ) had been diagnosed with signs of hypothyroidism. Of the 39 patients, eight $(n=8 / 39$ or $20.5 \%$ ) had been diagnosed with acute adrenal insufficiency (clinical signs and/or hyponatremia). We calculated the mean diagnostic delay for each clinical sign to determine the correlation between the diagnostic delay and the clinical signs. The mean diagnostic delay was $2.52 \pm 3$ months for agalactia, $8.3 \pm 8$ years for amenorrhea, $8.1 \pm 8.5$ years for hypothyroidism, and $10.6 \pm 9.4$ years for acute adrenal insufficiency. There was a correlation between the diagnostic delay and the clinical sign suggesting hypopituitarism. Indeed, we found a significantly shorter diagnostic delay, $<6$ months, for agalactia in comparison with the delay for other signs ( $P=0.002$ with the Mann-Whitney $U$ test).

For some patients, a SS diagnosis was suggested after a long delay: for instance, patient no. 4 was eventually diagnosed 9 years after delivery, despite two previous episodes of acute adrenocortical insufficiency and recurrent complaints of intense fatigue diagnosed as depression. Patient nos 37 and 39 were respectively admitted to the hospital 17 and 18 years after delivery for asthenia, nausea, vomiting, and consciousness disorders. The blood test revealed hyponatremia, which was completely reversed after replacement hormonotherapy. Fifteen patients $(38.4 \%)$ had consulted for a major complaint of asthenia. SS was suspected in one patient (patient no. 16) by a dermatologist on a diagnosis of dry skin, with associated amenorrhea and asthenia since the last delivery.

Of note is the fact that since the delivery, several patients had complaints that could have pointed to a

Table 2 Early signs that could have helped diagnose SS earlier in 28 patients with a diagnostic delay of more than 1 year.

\begin{tabular}{|c|c|c|c|c|c|c|}
\hline Patients & PPH headaches & Agalactia & Amenorrhea & Hypothyroidism & AAI & A \\
\hline 1 & $Y$ & $\mathrm{Y}$ & HTT & $\mathrm{Y}$ & $\mathrm{N}$ & $Y$ \\
\hline 2 & $\mathrm{~N}$ & NA & HTT & $\mathrm{N}$ & $\mathrm{N}$ & $Y$ \\
\hline 3 & $Y$ & $Y$ & $\mathrm{~N}$ & $\mathrm{~N}$ & $Y$ & $\mathrm{~N}$ \\
\hline 4 & $Y$ & DA & $Y$ & $Y$ & $\mathrm{~N}$ & $Y$ \\
\hline 8 & $\mathrm{~N}$ & NA & $\mathrm{N}$ & $\mathrm{N}$ & $\mathrm{N}$ & $\mathrm{N}$ \\
\hline 9 & $\mathrm{~N}$ & $Y$ & $\mathrm{~N}$ & $\mathrm{~N}$ & $N$ & $\mathrm{~N}$ \\
\hline 10 & $\mathrm{~N}$ & NA & $Y$ & $Y$ & $\mathrm{~N}$ & $Y$ \\
\hline 12 & $N$ & $Y$ & $\mathrm{~N}$ & $Y$ & $\mathrm{~N}$ & $Y$ \\
\hline 13 & $\mathrm{~N}$ & $Y$ & $\mathrm{~N}$ & $\mathrm{~N}$ & $\mathrm{~N}$ & $\mathrm{~N}$ \\
\hline 14 & $\mathrm{~N}$ & $Y$ & HTT & $\mathrm{N}$ & $\mathrm{N}$ & $Y$ \\
\hline 15 & $\mathrm{~N}$ & NA & HTT & $\mathrm{N}$ & $\mathrm{N}$ & $\mathrm{N}$ \\
\hline 16 & $\mathrm{~N}$ & DA & $Y$ & $\mathrm{~N}$ & $\mathrm{~N}$ & $\mathrm{~N}$ \\
\hline 17 & $\mathrm{~N}$ & NA & $\mathrm{N}$ & $\mathrm{N}$ & $\mathrm{N}$ & $Y$ \\
\hline 19 & $\mathrm{~N}$ & NA & $\mathrm{N}$ & $\mathrm{N}$ & $\mathrm{N}$ & $\mathrm{N}$ \\
\hline 20 & $\mathrm{~N}$ & NA & $\mathrm{N}$ & $\mathrm{N}$ & $\mathrm{N}$ & $\mathrm{N}$ \\
\hline 22 & $\mathrm{~N}$ & $Y$ & $Y$ & $\mathrm{~N}$ & $\mathrm{~N}$ & $Y$ \\
\hline 23 & $\mathrm{~N}$ & $Y$ & $\mathrm{~N}$ & $\mathrm{~N}$ & $\mathrm{~N}$ & $\mathrm{~N}$ \\
\hline 24 & $Y$ & $Y$ & $\mathrm{~N}$ & $Y$ & $\mathrm{~N}$ & $Y$ \\
\hline 25 & $\mathrm{~N}$ & $Y$ & $\mathrm{~N}$ & $\mathrm{~N}$ & $\mathrm{~N}$ & $\mathrm{~N}$ \\
\hline 27 & $Y$ & $Y$ & $\mathrm{~N}$ & $\mathrm{~N}$ & $\mathrm{~N}$ & $\mathrm{~N}$ \\
\hline 30 & $Y$ & $Y$ & $Y$ & $\mathrm{~N}$ & $\mathrm{~N}$ & $Y$ \\
\hline 31 & $\mathrm{~N}$ & NA & $\mathrm{N}$ & $\mathrm{N}$ & $\mathrm{N}$ & $Y$ \\
\hline 32 & $\mathrm{~N}$ & NA & $\mathrm{N}$ & $\mathrm{N}$ & $\mathrm{N}$ & $\mathrm{N}$ \\
\hline 35 & $\mathrm{~N}$ & NA & $\mathrm{N}$ & $\mathrm{N}$ & $\mathrm{N}$ & $\mathrm{N}$ \\
\hline 36 & $\mathrm{~N}$ & NA & $Y$ & $\mathrm{~N}$ & $\mathrm{~N}$ & $\mathrm{~N}$ \\
\hline 37 & $\mathrm{~N}$ & NA & HTT & $Y$ & $\mathrm{~N}$ & $\mathrm{Y}$ \\
\hline 38 & $Y$ & $Y$ & $\mathrm{~N}$ & $Y$ & $\mathrm{~N}$ & $\mathrm{~N}$ \\
\hline 39 & $\mathrm{~N}$ & $Y$ & HTT & $\mathrm{N}$ & $\mathrm{N}$ & $\mathrm{N}$ \\
\hline
\end{tabular}

HTT, hysterectomy; DA, dopamine agonist; Y, yes; N, no; NA, not available; A, asthenia; AAl, acute adrenal insufficiency; PPH, postpartum hemorrhage. 
possible diagnosis of SS. Of the 39 patients, 28 with a diagnostic delay of more than 1 year were thus analyzed retrospectively. Among these 28 patients, 14 had presented agalactia, two patients could not be evaluated due to the use of medications (dopamine agonist), and data were missing for the other patients. Seven of 28 patients $(n=7 / 28$ or $25 \%)$ had headaches in the postpartum period, six of 22 assessable $(n=6 / 22$ or $27.3 \%)$ ones had amenorrhea, and seven of $28(n=7 / 28$ or $25 \%)$ had hypothyroidism. Of 28 patients, $12(n=12 / 28$ or $42.8 \%)$ had suffered from asthenia since their delivery, requiring naps and/or professional reorientation.

Table 2 summarizes the retrospective signs that were found between delivery and the time of the diagnosis of SS that could have helped diagnose SS earlier.

\section{Pituitary deficiencies}

Some hormonal data at the diagnosis of SS were available for 27 patients, but most of them were not complete. The mean hormone level and range are summarized in Table 3 for each pituitary axis. A gonadotroph evaluation was available for 15 patients (one was on contraceptive and data were missing for 11 patients). At the time of the diagnosis, $83 \%$ $(n=20 / 24)$ presented with a corticotroph deficiency, $80 \%(n=12 / 15)$ with a gonadotroph deficiency, $92 \%(n=23 / 25)$ with a thyrotroph deficiency, $95.6 \%$ $(n=22 / 23)$ with a somatotroph deficiency, and $58 \%$ $(n=14 / 24)$ with a lactotroph deficiency (defined by PRL levels $<3 \mathrm{ng} / \mathrm{ml}$ ). Table 4 summarizes the hormonal deficiencies of 27 patients with SS at the time of the

Table 3 Results of hormonal analysis of patients with SS at the time of the diagnosis.

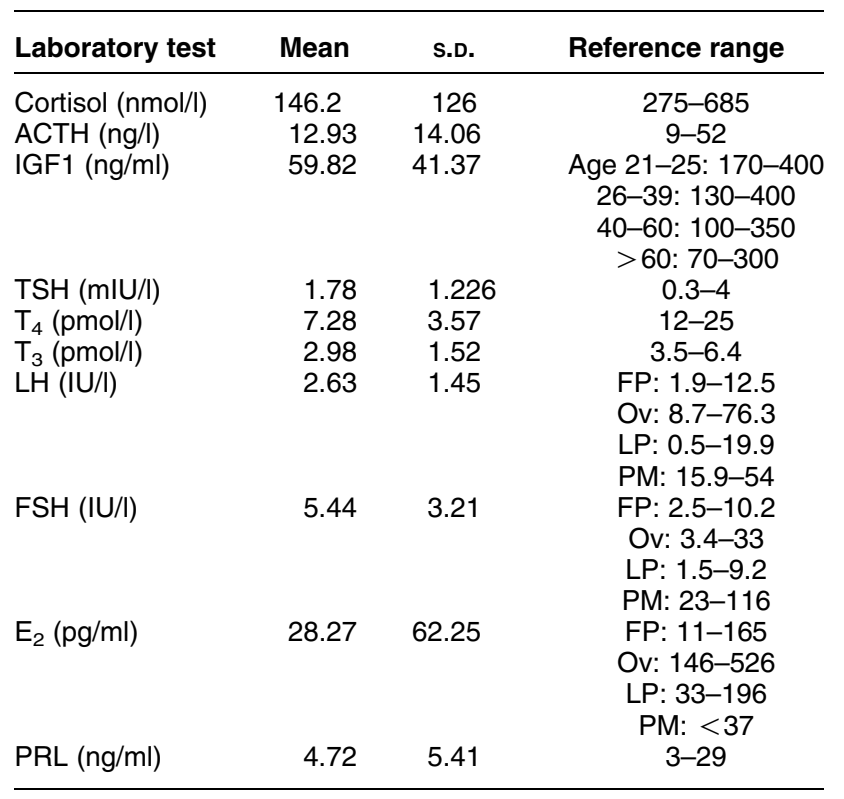

FP, follicular phase; Ov, ovulation; LP, luteal phase; PM, post-menopause. diagnosis. There was no correlation between the severity of $\mathrm{PPH}$ and the number of hormone axes affected ( $P=0.245$ with Spearman's test).

\section{Imaging data}

Thirty-eight patients had undergone pituitary MRI at the diagnosis of SS. One patient refused to undergo MRI because of claustrophobia and had undergone brain CT. Among the 38 patients who had undergone MRI, four had a normal MRI finding. Of the remaining 34 patients, 21 patients had a completely empty sella, one patient had a partially empty sella, and ten patients had pituitary atrophy. Two patients had a lack of enhancement after a gadolinium injection. There was no correlation between the MRI findings and the number of hormone axes affected $(P=0.312$ with the Mann-Whitney $U$ test).

\section{Discussion}

This study reports on the second SS cohort in a developed country after the one reported in the study carried out by Gei-Guardia et al. (13) in Costa Rica. In our study, the mean diagnostic delay was $9 \pm 9.7$ years. Our results, showing a long diagnostic delay of SS, are consistent with previous reports: $13.9 \pm 6.0$ years in the study carried out by Sert et al. (11) $(n=28), 13$ years in that by Gei-guardia et al. (13) $(n=60), 4.7 \pm 7.2$ years in that by Kristjansdottir et al. (10) $(n=7)$, and 16.3 \pm 4.7 years in that by Ozkan \& Colak $(12)(n=20)$. It can be observed that the diagnostic delay in our cohort and in cohorts in developed countries was long, probably because of several reasons. First, we can observe variable degrees of hypopituitarism, resulting in variable signs $(11,16)$. Most women with SS are asymptomatic until a stressful event occurs and precipitates adrenal insufficiency, hypothyroidism, or coma in them, which is another reason for explaining the diagnostic delay (14). This is probably also because patients with ACTH deficiency still produce aldosterone, in contrast to patients suffering from peripheral adrenal insufficiency (for whom clinical signs are usually more severe). According to several studies and our study, agalactia and amenorrhea seem to be classical signs of and important clues to SS. However, our study suggests that these two call signs are not systematically sought or are sought with difficulty after PPH when women are hysterectomized $(27.8 \%)$ and transferred to the ICU $(62 \%)$, where breastfeeding is not even considered.

Another hypothesis to explain the long delay in the diagnosis of SS is that most signs of SS are aspecific, especially during the postpartum period. Indeed, all women present with asthenia and weakness after delivery and can be misdiagnosed as having baby blues or depression (12). However, given the rarity of $\mathrm{SS}$, it is impossible to perform an anterior pituitary test 
Table 4 Hormonal deficiencies of 27 patients with SS at the time of the diagnosis.

\begin{tabular}{|c|c|c|c|c|c|c|}
\hline Patients & $\begin{array}{c}\text { PRL } \\
\text { deficiency }\end{array}$ & $\begin{array}{c}\text { Gonadotroph } \\
\text { deficiency }\end{array}$ & $\begin{array}{c}\text { Corticotroph } \\
\text { deficiency }\end{array}$ & $\begin{array}{c}\text { Somatotroph } \\
\text { deficiency }\end{array}$ & $\begin{array}{l}\text { Test } \\
\text { hgpo }\end{array}$ & $\begin{array}{l}\text { Thyrotroph } \\
\text { deficiency }\end{array}$ \\
\hline 3 & $Y$ & $Y$ & $Y$ & $Y$ & $\mathrm{Neg}$ & $Y$ \\
\hline 4 & $\mathrm{~N}$ & NA & $Y$ & $Y$ & $\mathrm{Neg}$ & $Y$ \\
\hline 8 & $Y$ & $Y$ & $\mathrm{~N}$ & $\mathrm{Y}$ & $\mathrm{Neg}$ & $\mathrm{N}$ \\
\hline 10 & $\mathrm{~N}$ & $Y$ & $Y$ & $Y$ & NA & $Y$ \\
\hline 11 & $\mathrm{~N}$ & $Y$ & $Y$ & $Y$ & $\mathrm{Neg}$ & $Y$ \\
\hline 12 & $\mathrm{~N}$ & NA & $Y$ & $Y$ & $\mathrm{Neg}$ & $Y$ \\
\hline 13 & $Y$ & NA & NA & NA & NA & $Y$ \\
\hline 14 & NA & NA & $Y$ & $Y$ & NA & $Y$ \\
\hline 15 & $\mathrm{~N}$ & $\mathrm{~N}$ & NA & $\mathrm{N}$ & NA & $Y$ \\
\hline 17 & $Y$ & $Y$ & $Y$ & $Y$ & NA & $Y$ \\
\hline 18 & $Y$ & $Y$ & $\mathrm{~N}$ & $Y$ & NA & $Y$ \\
\hline 22 & $\mathrm{~N}$ & NA & $Y$ & $Y$ & $\mathrm{Neg}$ & NA \\
\hline 24 & $Y$ & NA & $Y$ & NA & NA & $Y$ \\
\hline 25 & $Y$ & $Y$ & $Y$ & $Y$ & NA & $Y$ \\
\hline 26 & $\mathrm{~N}$ & $Y$ & $Y$ & $Y$ & NA & $Y$ \\
\hline 28 & $Y$ & $Y$ & $Y$ & $Y$ & $\mathrm{Neg}$ & $Y$ \\
\hline 29 & $Y$ & $Y$ & $Y$ & NA & NA & $Y$ \\
\hline 30 & NA & NA & $Y$ & $Y$ & $\mathrm{Neg}$ & $Y$ \\
\hline 31 & $Y$ & $Y$ & $\mathrm{~N}$ & $Y$ & $\mathrm{Neg}$ & $Y$ \\
\hline 32 & $Y$ & $Y$ & $\mathrm{~N}$ & NA & NA & $Y$ \\
\hline 33 & $\mathrm{~N}$ & NA & $Y$ & $Y$ & NA & $Y$ \\
\hline 34 & $\mathrm{~N}$ & NA & $Y$ & $Y$ & $\mathrm{Neg}$ & $Y$ \\
\hline 35 & $Y$ & $\mathrm{~N}$ & $Y$ & $Y$ & NA & $Y$ \\
\hline 36 & $Y$ & NA & $Y$ & $Y$ & $\mathrm{Neg}$ & NA \\
\hline 37 & $\mathrm{~N}$ & NA & $Y$ & $Y$ & $\mathrm{Neg}$ & $Y$ \\
\hline 38 & $Y$ & $\mathrm{~N}$ & $Y$ & $Y$ & NA & $Y$ \\
\hline 39 & NA & NA & NA & $Y$ & $\mathrm{Neq}$ & $\mathrm{N}$ \\
\hline
\end{tabular}

Y, yes; N, no; NA, not available; Neg, negative; test hgpo, insulin tolerance test; hypoglycemia (a test 'hgpo negative' suggests GH deficiency).

among all the tired women. An additional cause of misdiagnosis is that SS is so rare that it is not well known among physicians and midwives, which can explain the long diagnostic delay. Some cases of women with an early SS diagnosis during the postpartum period have been reported in the literature. We can observe that these women often presented with hyponatremia, reflecting a severe corticotroph deficiency, and/or had severe headaches after delivery, corresponding to the acute pituitary apoplexy $(17,18)$. In our study, $25 \%$ of the patients $(n=7 / 28)$ had headaches during the postpartum period.

In our study, we could not obtain data on the estimated blood loss and the degree of the severity of PPH was suggested by the presence or absence of transfusion, hysterectomy, and ICU admission. Among the patients for whom information was collected, $83.9 \%$ were transfused, $37 \%$ were hysterectomized, and $62 \%$ were admitted to the ICU. These results suggest that a majority of deliveries were extremely hemorrhagic. Patient nos 17, 26, and 38 had presented PPH, but they were not transfused, hysterectomized, or transferred to the ICU. Among these three patients, two had headaches and visual disturbance after delivery. These signs could have been suggestive of lymphocytic hypophysitis. Headaches have, however, been reported in up to $25 \%$ of the patients with SS, and neither patient showed signs in favor of an autoimmune condition. We thus decided that the most likely diagnosis was SS, which remains the first diagnosis to think of after PPH. Of note, some obstetrical data were obtained from endocrinology files because the obstetrical records were old and unavailable. Indeed, patient nos 17, 26, and 38 had given birth respectively in 1976, 2000, and 2002. Obstetrical data were probably incomplete. We, however, obtained some information that could suggest a severe PPH. Patient no. 17 had an acute C-section, with high amounts of blood loss, followed by a convulsive crisis, which would have resulted in brain hypoxia. Patient no. 26 had a retained placenta. Her blood test revealed a hemoglobin level of $12 \mathrm{~g} / \mathrm{dl}$ in the prepartum period and of $7.5 \mathrm{~g} / \mathrm{dl}$ in the postpartum period. The drop in hemoglobin was probably associated with severe hypotension, although this was not notified in the medical record. In patient no. 38, disseminated intravascular coagulation occurred during the delivery. We assumed that patient no. 38 had probably been transfused even if it was not recorded in the medical file. Although the short-term effects of hemorrhage are well known, the long-term effects such as SS seem to be unclear

SS is a very significant cause of maternal morbidity and mortality $(15,19)$. Whatever be the cause, Tomlinson et al. (20) showed that the mortality in patients with hypopituitarism was significantly higher than that in the general population. The study of 1034 adults with hypopituitarism showed that a GH deficiency was associated with an increased prevalence of 
cardiovascular risk factors and fractures and was associated with a decrease in the quality of life (21). In the study carried out by Kelestimur et al. (22), patients with SS were younger and had more severe $\mathrm{GH}$ deficiency, resulting in a poorer quality of life, compared with patients with non-functional pituitary adenoma. The same study reported beneficial effects on the quality of life, body composition, and lipid profile in patients with SS after GH replacement therapy (22). Early diagnosis may thus improve the quality of life and reduce morbidity and mortality after the initiation of hormone replacement therapy.

In the present study, we observed that only $11 \%$ of the patients were diagnosed of having SS with agalactia, while all other patients presented agalactia retrospectively, and they could have been diagnosed earlier. When we studied patients with a diagnostic delay of more than 1 year, we indeed found that $100 \%$ of the assessable patients had presented agalactia. This is a retrospective study, and some data were missing because several patients did not remember lactating. In France, the rate of breastfeeding is low compared with that in other countries $(37 \%$ in 1972 and $63 \%$ in 2010), and women failing to breastfeed are often not very concerned (23). In France, breastfeeding needs to be strongly promoted. Our study also revealed a significantly shorter diagnostic delay, $<6$ months, for agalactia in comparison with the delay for other signs $(P=0.002)$. Agalactia is thus the sign to systematically look for after a severe PPH. This would allow a more frequent and earlier diagnosis of patients with SS. Moreover, PRL is the only hormone that can be evaluated in the postpartum period because an increase in PRL secretion $(500 \mathrm{ng} / \mathrm{ml})$ is observed during pregnancy and the postpartum period, which is very important for lactation, and a return of the PRL level to the normal range 6 weeks after delivery can be observed when a woman does not breastfeed (24). We can thus suggest that all women presenting with agalactia during the postpartum period after a severe $\mathrm{PPH}$ should be evaluated by measuring serum PRL levels. If the blood test reveals a low level of PRL, a complete anterior pituitary test should be performed, including the measurement of free $\mathrm{T}_{4}$, TSH, $0800 \mathrm{~h}$ ACTH-cortisol, and IGF1 levels and MRI, to confirm the diagnosis of SS.

In our study, several women had been diagnosed with hypothyroidism or adrenal insufficiency based on aspecific signs such as asthenia. For many years, they had, therefore, received an incomplete treatment of hormone replacement (glucocorticoids or thyroid hormone), which can explain the persistent asthenia. SS should be suspected based on signs such as asthenia and amenorrhea, even several years after $\mathrm{PPH}$, warranting a test including the measurement of free $\mathrm{T}_{4}$, TSH, $0800 \mathrm{~h} \mathrm{ACTH-cortisol,} \mathrm{and} \mathrm{IGF1} \mathrm{levels.}$

It would be interesting to carry out a prospective study on SS incidence in case of severe PPH in Europe. Feinberg et al. (9) prospectively evaluated a cohort of patients with PPH. Of 55 patients, 15 (25\%) had two or more symptoms that suggested hypopituitarism, but nonetheless did not show pituitary dysfunction. Even if there was a $55 \%$ response rate, the authors concluded that SS is very uncommon nowadays.

In conclusion, the incidence of SS is very low. However, given the long diagnostic delay and the morbidity and mortality in cases of untreated hypopituitarism, women after severe $\mathrm{PPH}$ with agalactia should be evaluated by measuring serum PRL levels in the postpartum period. Women showing signs suggesting hypopituitarism even several years after $\mathrm{PPH}$ should be evaluated at least by the determination of $\mathrm{T}_{4}$, TSH, IGFI, $0800 \mathrm{~h}$ ACTH-cortisol levels.

\section{Declaration of interest}

The authors declare that there is no conflict of interest that could be perceived as prejudicing the impartiality of the research reported.

\section{Funding}

This research did not receive any specific grant from any funding agency in the public, commercial, or not-for-profit sector.

\section{Author contribution statement}

C Ramiandrasoa, F Castinetti, and B Courbière designed the study and co-wrote the first draft of the manuscript. C Ramiandrasoa, T Brue, P Fenichel, I Raingeard, and O Chabre were involved in the collection of data. C Ramiandrasoa, B Courbière, and F Castinetti contributed to the analysis of data and critically revised the pre-final draft. All authors reviewed the final draft and gave final approval before submission. All individuals who contributed to this study are either included as authors or are acknowledged at the end of the paper.

\section{Acknowledgements}

The authors thank Dr Sylvie Hieronimus for her contribution to data collection. They also thank Isabelle Marchesi and Stéphanie Jouvel for English language revision of the manuscript.

\section{References}

1 Fernandez H, Djanhan Y \& Papiernik E. Maternal mortality caused by hemorrhage in developing countries. What policy is proposed? Journal de Gynécologie, Obstétrique et Biologie de la Reproduction 198817 687-692.

2 Subtil D, Sommé A, Ardiet E \& Depret-Mosser S. Postpartum hemorrhage: frequency, consequences in terms of health status, and risk factors before delivery. Journal de Gynécologie, Obstétrique et Biologie de la Reproduction 200433 (Suppl 8) 4S9-4S16.

3 Zhang W-H, Alexander S, Bouvier-Colle M-H \& Macfarlane A. Incidence of severe pre-eclampsia, postpartum haemorrhage and sepsis as a surrogate marker for severe maternal morbidity in a European population-based study: the MOMS-B survey. BJOG: an International Journal of Obstetrics and Gynaecology 2005 112 89-96. (doi:10.1111/j.1471-0528.2004.00303.x)

4 Bouvier-Colle M-H, Saucedo M \& Deneux-Tharaux C. The confidential enquiries into maternal deaths, 1996-2006 in France: what consequences for the obstetrical care? Journal de Gynécologie, Obstétrique et Biologie de la Reproduction $2011 \mathbf{4 0}$ 87-102. (doi:10.1016/j.jgyn.2010.12.007) 
5 Sheehan HL. Post-partum necrosis of the anterior pituitary. Irish Journal of Medical Science 194823 241-255.

6 Sheehan HL. The frequency of post-partum hypopituitarism. Journal of Obstetrics and Gynaecology of the British Commonwealth $1965 \mathbf{7 2}$ 103-111. (doi:10.1111/j.1471-0528.1965. tb01380.x)

7 Zargar AH, Singh B, Laway BA, Masoodi SR, Wani AI \& Bashir MI. Epidemiologic aspects of postpartum pituitary hypofunction (Sheehan's syndrome). Fertility and Sterility 200584 523-528. (doi:10.1016/j.fertnstert.2005.02.022)

8 Kovacs K. Sheehan's syndrome. Lancet $2003361520-522$. (doi:10.1016/S0140-6736(03)12490-7)

9 Feinberg EC, Molitch ME, Endres LK \& Peaceman AM. The incidence of Sheehan's syndrome after obstetric hemorrhage. Fertility and Sterility 200584 975-979. (doi:10.1016/j.fertnstert. 2005.04.034)

10 Kristjansdottir HL, Bodvarsdottir SP \& Sigurjonsdottir HA Sheehan's syndrome in modern times: a nationwide retrospective study in Iceland. European Journal of Endocrinology $2011 \mathbf{1 6 4}$ 349-354. (doi:10.1530/EJE-10-1004)

11 Sert M, Tetiker T, Kirim S \& Kocak M. Clinical report of 28 patients with Sheehan's syndrome. Endocrine Journal 200350 297-301. (doi:10.1507/endocrj.50.297)

12 Ozkan Y \& Colak R. Sheehan's syndrome: clinical and laboratory evaluation of 20 cases. Neuro Endocrinology Letters 200526 $257-260$

13 Gei-Guardia O, Soto-Herrera E, Gei-Brealey A \& Chen-Ku CH. Sheehan's syndrome in Costa Rica: clinical experience with 60 cases. Endocrine Practice 201117 337-344. (doi:10.4158/ EP10145.OR)

14 Brichler S, Louahidi K, Lefort A, Bardet P \& Beyne P. Sheehan's syndrome manifested by cortisolemia. Annales de Biologie Clinique $200260599-601$.

15 Sayarlioglu H, Erkoc R, Sayarlioglu M, Dogan E, Kara PS \& Begenik H. Sheehan's syndrome presented with acute renal failure associated with rhabdomyolysis and hyponatraemia. Nephrology, Dialysis, Transplantation 200621 827-828. (doi:10.1093/ndt/ gfi234)

16 Shivaprasad C. Sheehan's syndrome: newer advances. Indian Journal of Endocrinology and Metabolism 201115 (Suppl 3) S203-S207. (doi:10.4103/2230-8210.84869)
17 Kaplun J, Fratila C, Ferenczi A, Yang WC, Lantos G, Fleckman AM \& Schubart UK. Sequential pituitary MR imaging in Sheehan's syndrome: report of 2 cases. AJNR. American Journal of Neuroradiology 200829 941-943. (doi:10.3174/ajnr.A1016)

18 Schrager S \& Sabo L. Sheehan's syndrome: a rare complication of postpartum hemorrhage. Journal of the American Board of Family Practice 200114 389-391.

19 Bao SS \& Fisher SJ. Repairing a "broken heart" with hormone replacement therapy: case report of cardiogenic shock due to undiagnosed pituitary insufficiency. Endocrine Practice 201218 e26-e31. (doi:10.4158/EP11284.CR)

20 Tomlinson JW, Holden N, Hills RK, Wheatley K, Clayton RN, Bates AS, Sheppard MC \& Stewart PM. Association between premature mortality and hypopituitarism. West Midlands Prospective Hypopituitary Study Group. Lancet 2001357 425-431. (doi:10.1016/S0140-6736(00)04006-X)

21 Abs R, Bengtsson BA, Hernberg-Stâhl E, Monson JP, Tauber JP, Wilton P \& Wster C. GH replacement in 1034 growth hormone deficient hypopituitary adults: demographic and clinical characteristics, dosing and safety. Clinical Endocrinology 199950 703-713. (doi:10.1046/j.1365-2265.1999.00695.x)

22 Kelestimur F, Jonsson P, Molvalilar S, Gomez JM, Auernhammer CJ, Colak R, Koltowska-Hggstrm M \& Goth MI. Sheehan's syndrome: baseline characteristics and effect of 2 years of growth hormone replacement therapy in 91 patients in KIMS - Pfizer International Metabolic Database. European Journal of Endocrinology 2005152 581-587. (doi:10.1530/eje.1.01881)

23 Blondel B, Lelong N, Kermarrec M, Goffinet F \& National Coordination Group of the National Perinatal Surveys. Trends in perinatal health in France from 1995 to 2010. Results from the French National Perinatal Surveys. Journal de Gynécologie, Obstétrique et Biologie de la Reproduction 201241 e1-e15. (doi:10.1016/j.jgyn.2012.04.014)

24 Karaca Z, Tanriverdi F, Unluhizarci K \& Kelestimur F. Pregnancy and pituitary disorders. European Journal of Endocrinology 2010 162 453-475. (doi:10.1530/EJE-09-0923)

Received 3 April 2013

Revised version received 2 June 2013

Accepted 10 July 2013 